\title{
Mitogenic Action of Prolactin on the Pancreatic Islet Cells in the Chick*
}

\author{
B. R. Maiti, Subrata Chakraborty and Asok Boral \\ Histophysiology Laboratory, Department of Zoology, University of Calcutta, India \\ Received January 18, 1982
}

\begin{abstract}
Summary. A histological investigation was made to elucidate whether mammalian (ovine) prolactin can induce mitotic activity in pancreatic islet cell (in splenic lobe) of chicks. Prolactin treatment in different dosages (total dosage : 15, 50 and $100 \mathrm{IU}$ per bird in 10 days) increased the mitotic frequency and also caused hypertrophy in the AF-positive cells of the $B$-islets in the splenic lobe. The increase in mitotic frequency was uniform for all doses applied. It is suggested that prolactin has a mitogenic action on the pancreatic islet cells of male chicks and that action is possibly not dose-dependent.
\end{abstract}

Prolactin is reported to act as a potent mitotic stimulator in several endocrine tissues in chicks (Chakraborty and Maiti, 1981; Maiti and Bose-Mitra, 1980; Maiti and Chakraborty, 1980, 1981; Maiti and Mukherjee, 1982). Consequently it seemed interesting to ascertain whether prolactin can also induce mitotic activity in the pancreatic islets in chicks.

It is, however, known that prolactin causes hyperglycemia in birds (RIDDLE et al., 1947; Kobayashi, 1953; Maiti and Bose-Mitra, 1980). However, it is not fully known whether prolactin can also modify the islet cytology of the pancreas in birds. Only information by MILLER (1942) has shown that prolactin does stimulate pancreatic islet cells in the pigeon.

In view of the above, prolactin action on islet cytology of the pancreas was investigated from histological and karyodynamic standpoints in the chick.

\section{MATERIALS AND METHODS}

Fifteen-day old Leghorn cockerels (body weight 70-80g) were procured from a local poultry farm and maintained under controlled laboratory conditions (temperature: $28^{\circ} \mathrm{C}$ $\pm 2^{\circ} \mathrm{C}$, lights on at $06.00 \mathrm{hrs}$ to $18.00 \mathrm{hrs}$ ). The chicks were fed with a standard poultry feed and water ad libitum. The forty chicks were divided equally into 4 groups. Three groups were injected intramuscularly with prolactin (NIH-LTH) in three differert doses, viz., 1.5 i.u./bird, 5 i.u./bird and 10 i.u./bird, daily for 10 consecutive days. The

*This work was supported, in part, by a grant from the Special Assistance Programme of the University Grants Commission, Government of India, to the Department of Zoology, University of Calcutta. 
remaining group received normal saline injections and served as a control.

All the birds received colchicine by intraperitoneal injection $(0.1 \mathrm{mg} / 100 \mathrm{~g}$ body weight) $5 \mathrm{hrs}$ prior to autopsy. Colchicine was administered from 11.00 p. m. to 4.00 a. $\mathrm{m}$. since the mitotic rate in the birds was highest during this period (MAITI, 1968).

The birds were killed by cervical dislocation on the 11th day of the experiment. The splenic lobe of the pancreas was dissected out and fixed in Bouin's fixative. The tissues were sectioned at $5 \mu \mathrm{m}$ following routine microtomy. The sections were stained by aldehyde-fuchsin (EPPLE, 1967) and phosphotungstic acid-haematoxylin (LEvENE and FANG, 1964) for histological study of the different cellular elements in the islet tissue. Iron alum-haematoxylin stain was also employed for the demonstration of mitotic figures.

At least 3,000 cells (mitotic and non-mitotic) were counted at random from both Aand B-islets of the splenic lobe of the pancreas of each specimen. The mitotic cell percent was calculated in relation to non-mitotic cells. The data was analysed following Student's 't' test (SNEDECOR, 1957).

\section{RESULTS}

\section{Histology}

Control: The microscopic anatomy of the chicken pancreatic islets has been extensively described (OAKberg, 1949; Mikami and Ono, 1962; Mikami and Mutoh, 1971; Smith, 1974; Bonner-WeIr and WeIr, 1979). The present study shows that in 25 dayold chicks, the splenic lobe contains a few A-islets (composed mostly of a PTAHpositive cells) surrounded by many B-islets (composed mainly of aldehyde-fuchsin-positive cells and few moderately PTAH-positive cells) of small and moderate size. The A-islets are irregular in shape and often multilobed and are larger than the B-islets.

Treated: Prolactin treatment increased cell and nuclear size particularly in the aldehyde-fuchson-positive B-cells of the B-islets of the splenic lobe. These changes were marked in almost all the doses (viz., 1.5 i.u., 5.0 i.u., or 10 i.u., daily per bird) of prolactin treatments. No appreciable change was marked in the A-islets of the pancreatic lobe.

\section{Mitotic incidence}

Control: In contrast to the presence of mitotic figures only in the central part of the B-islets in the chick embryo (Swenne and Lundqvist, 1980), in 25 day-old chicks the mitotic figures were found irregularly in both the A- and B-islets (Fig. 1) of the splenic lobe. The number of these cells was smaller in the A-islets than in the B-islets.

Treated: Prolactin treatment in all the doses (viz., 1.5 i.u., 5 i.u. and 10 i.u. per bird daily, for 10 days) almost uniformly and significantly increased the mitotic frequency particularly in the B-islets of the splenic lobe (Fig. 3). The mitotic response was greater in the aldehyde-fuchsin-positive B-cells (Fig. 2). No appreciable change was observed in the mitotic frequency in the A-islet cells after treatment.

\section{DISCUSSION}

The present investigation reveals that mammalian (ovine) prolactin promotes mitosis in the pancreatic islets of the splenic lobe in any dosage administered. Our present observation is along the line of earlier reports that prolactin has a mitogenic action in 


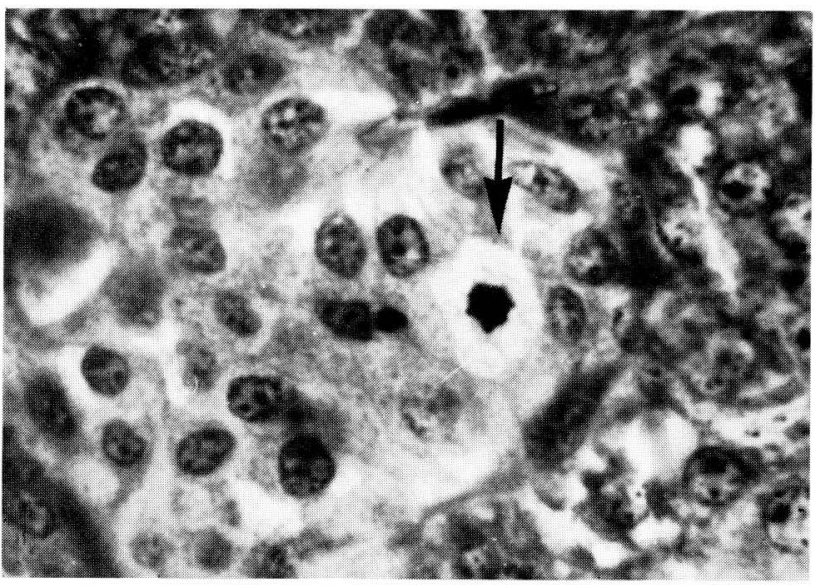

Fig. 1. A section of the splenic lobe of the chick (control) pancreas showing a metaphase cell (arrow) in the B-islet. $\times 1,300$

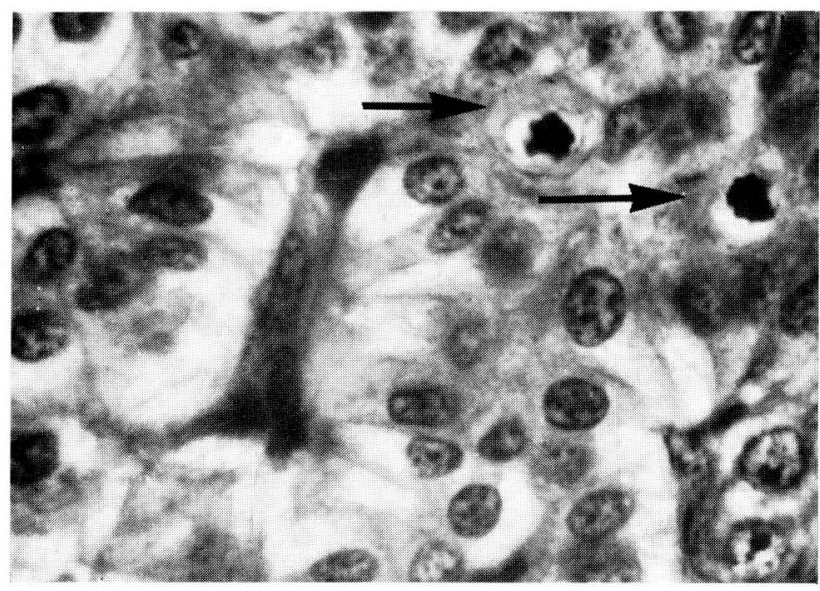

Fig. 2. Increased mitotic cells (arrows) in the B-islet of the splenic lobe of the pancreas after treatment with prolactin in the chick. Hypertrophied cells and nuclei are also seen. $\times 1,300$

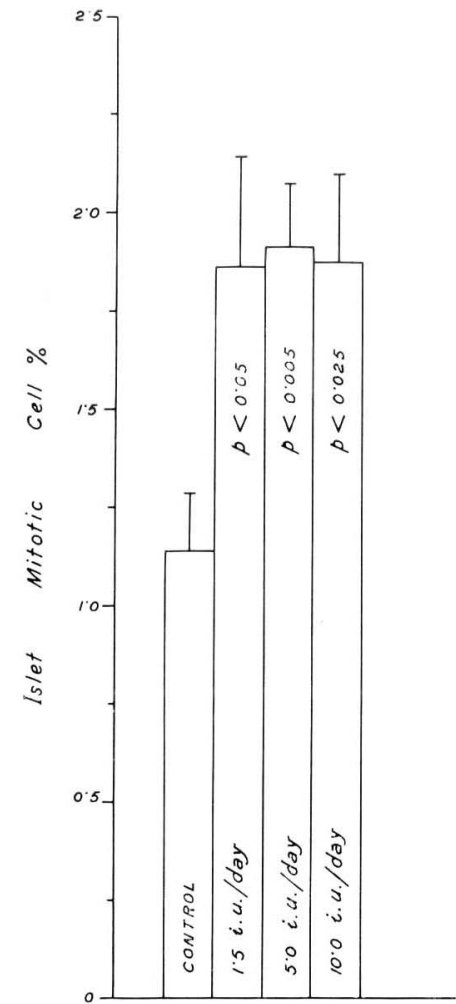

Fig. 3. Histograms showing the frequency of mitotic cells $(\%)$ in the control and prolactin-treated chicks. Note an almost identical increase in the metaphase cell frequency $(\%)$ among the three different doses of prolactin treatment in chicks. The vertical bar represents the standard error of the mean value. P-values are shown within the histograms.

most of the endocrine organs of chicks (Chakraborty and Maiti, 1981; Maiti and Chakraborty, 1980, 1981; Maiti and Mukherjee, 1982). However, it is apparent that prolactin action on mitotic activity is not dose-dependent since the mitotic response of the islet cells to prolactin remained almost uniform even with higher dosages, unlike that observed in other endocrine organs (Chakraborty and Maiti, 1981; Maiti and Chakraborty, 1981). In this study, the histological picture of cell activation in the B-islets following prolactin treatment corresponds to earlier work with pigeon (Miller, 1942). Thus, it is apparent for both cytological and mitotic studies that prolactin acts preferably on the AF-positive- B-islet cells of the endocrine pancreas of chicks.

Acknowledgements. We wish to thank Asok GHosh, F. N. A., Sir Nilratan Sircar Professor of 
Zoology, University of Calcutta, for his interest in this work. The free gift of purified ovine prolactin (NIH-LTH) from the National Institute of Health, Bethesda, Maryland, U. S. A., is also gratefully acknowledged.

\section{REFERENCES}

Bonner-Weir, S. and G. C. Weir: The organization of the endocrine pancreas: A hypothetical unifying view of the phylogenetic differences. Gen. comp. Endocrinol. 38: 28-37 (1979).

Chakraborty, S. and B. R. Maiti: Influence of prolactin on pineal gland activity in chicks. Gen. comp. Endocrinol. 44: 226-229 (1981).

Epple, A.: A staining sequence of A, B and D cells of pancreatic islets. Stain Technol. 42: 53-61 (1967).

Kobayashi, H.: Inhibitory effect of lactogen on moulting. Jap. J. Zool. 11: 21-26 (1953).

Levene, C. and P. Fang: Critical staining of pancreatic alpha granules with phosphotungstic acid haematoxylin. Stain Technol. 39: 39-44 (1964).

Maiti, B. R.: Cellular dynamics of the uropygial gland in the pigeon. Fol. biol. (Krakow) 16: 49-54 (1968).

Maiti, B. R. and K. Bose (Mitra): Adrenomedullary and glycemic responses to prolactin in chicks. Mikroskopie 36: 107-113 (1980).

Maiti, B. R. and S. Chakraborty: The mitogenic action of prolactin on some endocrine organs of chicks. Arch. histol. jap. 43: 341-346 (1980).

: Prolactin-induced mitotic activity in the anterior pituitary gland of chicks. Arch. histol. jap. 44: 251-255 (1981).

Maiti, B. R. and R. Mukherjee: Adrenocortical responses to prolactin in chicks. Mikroskopie 39: 132-138 (1982).

Mikami, S. I. and K. Mutoh: Light and electron microscopic study of the pancreatic islet cells in the chicken under normal and experimental conditions. Z. Zellforsch. 166: 205-227 (1971).

Mikami, S. I. and K. Ono: Glucagon deficiency induced by extirpation of alpha islets of the fowl pancreas. Endocrinology 71: 464-473 (1962).

Miller, R. A.: Effects of anterior pituitary preparation and insulin on islet cells of the pigeon pancreas. Endocrinology 31: 535-544 (1942).

Oakberg, E. F.: Quantitative studies of pancreas and islets of Langerhans in relation to age, sex and body weight in white leghorn chickens. Amer. J. Anat. 84: 279-310 (1949).

Riddle, O., D. F. Opdyke, R. W. Bates, L. B. Dotti, E. F. Vischer and H. R. Marvin: Studies on carbohydrate and fat metabolism. Carnegie Inst. Washington Publication No. 569, 1947 (p. 1128).

Smith, P. H.: Pancreatic islet of the coturnix quail. A light and electron microscopic study with special reference to islet organ of the splenic lobe. Anat. Rec. 178: 567-586 (1974).

Snedecor, G. W: Statistical methods. The Iowa State College Press, Ames, Iowa, 1957.

Swenne, I. and G. Lundqvist: Islet structure and pancreatic hormone content of the developing chick embryo. Gen. comp. Endocrinol. 41: 190-198 (1980).

Dr. B. R. MAITI

Histophysiology Laboratory

Department of Zoology

University of Calcutta

35 Ballygunge Circular Road

Calcutta 700019

India 